\title{
Beyond Teaching Methods: A Complexity Approach
}

\author{
BERNARD RICCA \\ Saint John Fisher College (USA)
}

\begin{abstract}
A complexivist perspective to teaching critiques the commonplace teaching "methods" and illuminates alternative approaches to teaching and teacher preparation. Focusing on system growth, the mutual influence of systems on one another, and nonlinear connectedness of systems, this paper defines four important components to teaching: A need for mutual influence among teachers, students, the content being taught and the curriculum; enculturation into a scholarly community; reflection on the part of teachers and students; and a need for teacher improvisation. The implication of these components for teacher preparation is then examined.
\end{abstract}

\section{Introduction}

It is obvious that commonplace teaching "methods" are ubiquitous in teaching. A quick perusal of teacher education programs will usually turn up required courses with "methods" in the title. While many of these methods are likely the descendants of Tyler's (1950) four criteria for good curriculum - goals, experiences, organization of those experiences, and assessment - there can be little doubt about the influence of these commonplace methods even today. Wiles (1952) noted that many people (and teachers) believed then:

Teaching consists of organizing knowledge into some pattern, of presenting the facts and generalizations in a clear, easily understood fashion, of testing to determine the amount of information acquired, and of marking the pupil's attainment ... any change from this pattern is a softening of the educative process, a departure from the fundamentals. They are concerned with better ways of telling, explaining, drilling, testing, and marking. (p. 11)

Many people (and teachers) continue to subscribe to these ideas. Even one of the more recent curriculum rages within education in the United States, "Understanding by Design" (Wiggins \& McTighe, 2005), contains essentially Tyler's four components, albeit in a "backwards design" ordering.

However, despite the widespread use of these commonplace methods, some have argued against them. There are many objections to commonplace methods, and they tend to revolve around the problem of designing a curriculum in the absence of actual students: the goals, assessments and experiences of school are chosen before the teacher knows the students. Doll (2002) states these objections this way: "[T]eaching in a methodized way removes the experiences of the learner, the learner's very being from 
the learning process" (p. 141). Arguments such as this raise questions about the role of the teacher in the classroom and about teacher preparation.

Complexity can provide a new lens through which to examine teaching methods. This examination can provide new ways of framing critiques and even evoke new critiques of commonplace methods. Complexity can also shine light on places to look for better approaches to education than conforming to pre-selected methods.

\section{Complexity}

A former President of the Santa Fe Institute, Ellen Goldberg, once adapted an old saw about economists when she said "[a]sk six complexivists what 'complexity' is and you'll get seven different answers" (2003, personal communication). Indeed, many different (although usually somewhat related) approaches to complexity exist in the literature (compare, for example, the approaches of Bertuglia \& Vaio, 2005; Cilliers, 1998; Davis \& Sumara, 2006; Stewart \& Cohen, 1995; Waldrop, 1992; see Alhadeff-Jones, 2008, for a historical perspective), and there is currently no consensus about which one is "best" or "appropriate" in education. Hence, before moving forward, it is important to note what complexity will be taken to mean here. For purposes of this paper, a complex system is one that has three interrelated hallmarks: growth ${ }^{1}$, mutual influence, and nonlinear connectedness. While other approaches are possible - and I make no claim here that this approach to complexity is the approach - these three hallmarks sufficiently describe complex systems, include all the features necessary to distinguish a complex system from a non-complex one, are readily applicable to the topics of commonplace teaching methods and alternatives examined here.

Although these three hallmarks are examined sequentially - this sequential approach is a limitation of text as a medium - it must be noted that these three form a complex system, and therefore a piecemeal approach is a poor way to begin to understand them. Understanding of each one influences our understanding of the others, and there is no clear way to prioritize one over the other in order to make claims that begin "the most important characteristic of a complex system is...". Davis and Sumara (2006) call for the study of the properties of complex systems "all-at-once" ${ }^{2}$ and it is with this caveat in mind, we begin.

\section{Growth}

Complex systems grow organically; they are not systems assembled piece by piece as a car on an assembly line. Just as Dr. Frankenstein was able to assemble a monster, but not a human person, through his endeavors, systems that can be assembled by the action of an entity external to the system are not the types of grown systems that will be considered here. The idea of growing-complex systems has a number of important implications. Three are significant for this discussion.

Before examining complex systems in detail it is important to look at one archetype of complex systems, the Belousov-Zhabotinskii (B-Z) reaction (Prigogine, 1984). While this system appears to be complex, that is to some extent assembled, the system clearly results from an external chemist combining chemicals. This type of assembled-complex system is different in character from the growing-complex systems we will examine here. In the case of the $\mathrm{B}-\mathrm{Z}$ reaction, the external agent is responsible for placing the

\footnotetext{
${ }^{1}$ I will use the term growth even though other terms (e.g., evolving, developing, etc.) appear in the literature. While I recognize there are differences between, for example, a "growing system" and an "evolving system," the approach here will try to avoid making those differences important, and so growth should be an acceptable term.

${ }^{2}$ One anonymous reviewer of this paper wrote "allatonce," without the hyphens, when describing this approach. I believe that there is some merit in doing that.
} 
components of the reaction in proximity to each other, but the changing patterns of the system are not due to the external agent and the interactions between components are not determined by the external agent. However, the environment of the B-Z reaction is not a complex system. Instead, the experimenter feeds in reactants and removes products at a pre-planned rate. Furthermore, the B-Z reaction is substantially less complex - as determined by any appropriate measure one wishes to use - than students, classrooms, and the other entities examined in educational research. Although the details may be unpredictable, there is a set of reaction equations that can describe the gross behavior of the B-Z reaction and be used to closely simulate it (Winfree, 2010). No such set of equations exists for human persons or systems composed of sets of humans. Further refinements of the notion of complexity - developed below - will draw a clearer distinction between these types of assembled-complex systems and the growingcomplex systems that are of interest to us here.

First, growing-complex systems are "the result of a series of highly contingent events that would not happen again if we could rewind the tape" (Gould, quoted in Rosenberg, 1990, p. 1). Hence, the current state of a complex system is dependent on all of the events of its history. A complex system cannot be copied or fully understood without completely following the same history.

This need to include a complex system's full history argues against many randomized controlled trial experiments. The argument is both epistemological and procedural: We can no more "repeat" an experiment on a complex system than we can ask a class of fifth graders at the end of the school year to go back to the way they were at the beginning of the school year. However, the assumption in randomized controlled trial experiments is that the precise histories of systems are unimportant. Further, attempts to project the future of two complex-systems without including their full histories - even two systems that appear to be equivalent by some (partial) measures of their current characteristics - are doomed to fail except in the most trivial cases. Hence, the usual notions of validity and reliability that underlie modernist approaches to assessment, education and educational research need to be re-examined in the light of complexity.

Second, complex systems are autopoietic (Maturana \& Varela, 1992), meaning that they are self-directed and cannot easily be directed by external entities. Unlike a mechanical system, which responds to external forces in a (usually) predictable and determined manner, a growing system will respond to external stresses, but not in any determinable manner, and not normally in any way that can be controlled from the outside. While it is relatively easy to destroy an autopoietic system from outside the system, any parent or teacher can attest to the fact that moving a child to particular behaviors or thoughts is a very difficult task, and one at which even "good" parents and teachers are not always successful. Even attempts to change the components of a complex system, usually in an effort to "improve" the system, are difficult and not guaranteed to succeed. As an extreme case, consider the short-term and long-term difficulties involved in organ transplantation (which is also considered below).

Third, in a growing system all action is creative action (Kampis, 1991). In a growing system, creative action is not an exceptional state; creative action is the only state of action for these systems. These growing systems - which Kampis terms component systems - "build and destroy during their ordinary activity the material structures that serve as the basic components of the systems" (Kampis, 1991, p. 197). Even the maintenance of a complex system entails ongoing acts of creation. For example, the cells that compose a human body today are not the same cells that composed the body yesterday; today's cells were created from components taken from the environment. Growing systems are creative systems.

Taken together, these three properties of growing systems - historicity, autopoiesis, and creativity - point to some important issues. Growing systems can bring forth new 
entities; the interpretation of these new entities is problematic, and even the recognition of new entities is difficult. The ability of growing systems to create new entities prevents prediction. The inability to predict the future states of growing systems is an even more severe statement than is usually examined in chaos theory. Chaos theory prevents prediction because of the (exponential) growth of uncertainties over time. The ability to create new entities prevents prediction because measurement "... is only sensible when you know a good deal about what you are talking about" (Jones, 1981, p. 25). Not only is the ability to measure curtailed, the creation of new entities requires the creation of new interpretations and meanings. It makes sense, for example, to say that a baseball team scored zero runs. However, before elephants emerged on earth, it was not merely that there were "zero elephants." Instead, the concept "elephant" had no meaning. In fact, and this is particularly true in fields like chemistry and molecular biology, we can identify molecules only because we know what to look for; finding "novel" molecules is very difficult. ${ }^{3}$

It is also important to recognize that, in a human autopoietic system, the interpretations and meanings discussed could be those internal to a person or the more usually considered interpretations and meanings assigned by an external observer. Maturana and Varela (1992) give the following:

Imagine a person who has always lived in a submarine. He has never left it and has been trained how to handle it. Now, we are standing on the shore and see the submarine gracefully surfacing. We get on the radio and tell the navigator inside: "Congratulations! You avoided the reefs and surfaced beautifully"...The navigator in the submarine, however, is perplexed: "What's this about reefs and surfacing? All I did was push some levers and turn knobs and make certain relationships between indicators as I operated the levers and knobs." (pp. 136-137)

When the internal/external problem is combined with the creation of new entities, we come to an important issue: The external observer sees changes only in the characteristics that $\mathrm{s} /$ he is interested in and capable of noticing. For example, the "punctuated equilibrium" (Gould \& Eldredge, 1977) approach to evolution uses the existence of sudden jumps in the fossil record to claim that the evolutionary process is one of stability with occasional bursts of morphological change. However, it is likely that, even when there are no external changes in an organism, there are internal changes taking place in the genetic code. These changes do not always affect the gross structure seen in the fossil record, and so we do not see the subtle (and possibly not fitnessrelated) changes that set the stage for the later observable changes. Langton's ant simulation (1986) provides a concrete example of subtle internal changes in a system seemingly having no effect for a long period before there is a sudden (i.e., fast and unexpected) change in behavior that an external observer notices ${ }^{4}$. These types of sudden changes are often called "emergent behaviors" by the external observer, but it must be noted that - from the ant's (internal) perspective - nothing has changed. Indeed, it seems likely that the equilibrium perceived by the observer should not have been assigned to the ant to begin with; the experience of equilibrium and emergence may be in the observer rather than in the observed system (e.g., Crutchfield, 1994).

\footnotetext{
${ }^{3}$ This bears some relationship to Kuhn's work on scientific paradigms, and to Piaget's work on schema.

${ }^{4}$ Being a simulation, the "ant" is not aware of any sudden change at the time when the external observer notices change. It is unclear how an analogous situation works with human actors, but it is likely that there is an internal change in addition to the change observed from the outside.
} 


\section{Mutual interactions}

Relationships between complex systems exhibit a mutual influence of each system on the other (Kaneko, 2006) and provoke changes in both systems. This mutual influence is different from the usual modernist approach to interactions where a system of interest exists in an unchanging "environment" and where the closest that one usually comes to a mutual influence is to consider the system of interest using up resources from the environment.

If two systems interact without mutual influence, then at least one of the systems is participating as a non-complex system. For example, the computer on which I am composing this paper will be unchanged by the human-computer interaction once I remove my USB drive and walk away. Hence, the computer cannot be a complex system (even though it may be - to me - at times very unpredictable ${ }^{5}$ ). On the other hand, a deep conversation between friends generally results in irreversible changes in both partners, and this mutual influence indicates that both friends are complex systems. The irreversible nature of these changes is different from the changes that occur in the B-Z reaction, where unchanging atoms merely cycle between different types of molecules. Irreversibility in the case of the B-Z reaction only occurs in bulk, not in the individual (see Prigogine, 1984, for more on this notion of irreversibility). In growing-complex systems, mutual influence results in irreversible changes in individual entities.

Non-complex systems are categorically different from complex systems: noncomplex systems admit reductionism and, as is the usual case in thermodynamics, allow for the "environment" to be unchanged. In either of these cases, there can be interactions without mutual influence. However, in a complex system, attempts to reduce the system or deal with only part of the system, or to treat the system as unchanging, merely fragments the system and creates great stress within the autopoietic organization of the system, generally with negative consequences.

As one example of a fragmented complex system, consider an organ transplant, which is an attempt to (re-)assemble a complex system. In the process of transplantation, the host body - and the transplanted organ, which is also a complex system - attempt to maintain themselves as they were before the transplant. Therefore, great efforts are undertaken to help the transplant recipient's body "accept" the transplanted organ; these efforts are a measure of the stress of fragmentation and often result in unwanted consequences. The anti-rejection drugs necessary for the success of a transplant - which are generally a permanent necessity and come with other so-called "side effects" - also make the recipient much more susceptible to colds and other viruses because of the suppressed immune system. Attempts to engineer an autopoietic system, or to deal with it piecemeal, are problematic.

Nevertheless, as an autopoietic system cannot easily be directed from the outside, external agents will often attempt to deal with the system piecemeal in the hopes of achieving a certain goal. As an example, consider the ways in which a teacher may attempt to teach a student by requiring the student to focus only on the material of a lesson plan, and to stay "on task". In a subtle way, this reduction of the complexity of the student is an effort to control the learning of student, and in a not-very-subtle way, this is an attempt to disallow a mutual influence between the student and the material, thereby resulting in a "fragmented" student (and, as is well known, fragmented knowledge). Autopoietic systems cannot be controlled; an attempt to control pieces of the system will also generally fail.

Likewise, to remove part of a complex system and isolate it for, say, "closer study", is to remove the "pattern that connects" (Bateson, 1988). The isolated sub-system is easier to work with, perhaps, but, if so, it is no longer complex and is no longer the

\footnotetext{
${ }^{5}$ Ironically, I was listening to Frank Sinatra's recording of No One Ever Tells You while composing this.
} 
original system. For example, cell membranes taken from cells do not behave in the same way as they do in a cell. ${ }^{6}$ Likewise, a child taken from a classroom environment for assessment does not behave the same way as $\mathrm{s} /$ he does in a classroom and the attempt to understand the child's classroom behavior through such efforts is thwarted.

However, there is sometimes important learning that occurs through these reductionist endeavors. First, certain skills may be developed in isolation. Often, these skills involve something mechanical (think about a pianist practicing scales and cadences). Second, some intuitive hypotheses may be developed. We can learn about a sub-system of a complex system, and then, upon returning to the full system, the juxtaposition of expected behavior and actual behavior can offer a lens through which to interrogate the full system. Third, Holland (1998) notes that instead of attempting to reduce organization or behavior at one "level", we should recognize that one "level" may constrain occurrences at another level. For example, chemistry cannot be reduced to physics, but neither can chemistry violate physical principles.

The inability to gain much insight from a sub-system isolated from its entire system is true for children and classrooms. For example, even after a child undergoes long periods of counseling to "remedy" unwanted classroom behaviors, and can behave "successfully" outside of a classroom, behavior within the classroom may be unaffected. Seltzer-Kelly et al. (2011) note the following:

Mary Catherine Bateson reflects upon a videotaped family counseling session that she has watched repeatedly as part of her professional supervision of the counselor. The designated client is the child; however, over repeated viewings of the session, Bateson has found that her perspective as to the actual source of the problem has shifted several times. She began by seeing the child as the sole possessor of issues. She then moved toward considering the mother as the precipitating factor, then the father, and finally, after many viewings of the interactions in the session, has begun to wonder whether the therapist is really the one who is fomenting dysfunction. Finally, she explains, she has come to view the family dynamic in terms of Gregory Bateson's thought: to see the pathology as a product of the interaction of systems, rather than as residing in any individual. (p. 7)

Occurrences such as this can be taken as further evidence that autopoietically organized systems cannot be treated as assembled systems: Mutual influence (even among the complex systems that comprise the fuller system) is important.

In fact, the problem is actually much worse than this: It is an artifact of our starting point to consider a system as made up of components with mutual influences. To talk of the "components" of a system is already to (potentially) reduce the system to parts. In considering educational contexts, great care needs to be taken to consider components without falling into either reductionism or to what Kampis (1991) refers to as a metaphysical "slippage" between the epistemology of an approach and the manner in which that approach is put into practice. Autopoietic systems, as indicated earlier, cannot be controlled from the outside, so the question of what "influence" means in this context is still nebulous. The situation will get still more intricate, however, as we turn now to the topology of complex systems.

\section{Nonlinear connectedness}

Complex systems exist with connections that are different from non-complex systems. It is usual to think about various systems in a hierarchical fashion, with a top-level and various sub-levels leading to the bottom. In these situations, it is very true that the whole is the sum of the parts. A school district, for example, is often (erroneously) conceived of as being composed of schools, which are in turn made up of classrooms, which hold

\footnotetext{
${ }^{6}$ Indeed, one learns very little about cells from the study of cell membranes in vitro rather than in vivo.
} 
students. Linear, (nearly) closed systems are amenable to this type of analysis, and the success of much of physics and engineering testifies to the usefulness of this type of separability and reductionism. Indeed, the success of the Industrial Revolution relied on the ability to construct items from their parts. However, the types of systems we encounter in education are not amenable to such types of reductive or separable approaches. Human complex systems ${ }^{7}$ are not related to each other in such simple ways. Indeed, the approaches that allow us to think of the whole as a sum of parts fail to capture complex systems in two ways, one related to topology and one related to boundaries.

We begin our examination of connectedness by noting the difference between geometry, which is commonly taught in schools, and topology, which is not. Geometry is concerned with the measurement of shapes, and includes such things as length, volume, and the like. In geometry, there are clear scales that one can use in measurement, and comparisons between objects are relatively simple. Topology is not concerned with such things as lengths but instead is concerned with the notion of connections between objects, as in a network of friends. In this example, it is clear that whether or not two people have a friend in common is not dependent upon the physical location of the three people but rather upon some other relationship. Topology, then, can be seen to be an approach that relies on something other than a scale or metric.

First, we must consider the relationship of smaller systems to larger ones. Davis and Sumara (2006) envision an approach to complex systems that is different from separability and reductionism, embedding one system inside another, as a sort of matryoshka doll. Although their approach is an improvement over the reductionist one, it is still a globally linear one, with larger systems containing smaller ones and with different size systems often orderable according to the time scales ${ }^{8}$ on which they operate. In human complex systems, it is true that individuals make up classrooms, which make up schools, which make up society; and so the individual can be found within the society. However, it is also true that society can be found within the individual. Hence, there is not really a "largest" system, and instead of size of system, consideration of a different ordering is appropriate. Related to this is another issue, known as immergence. Andrighetto, et al. (2007) state:

Dealing with autonomous social agents, emergence is in the loop between bottom-up and top-down processes. Emergence of properties at aggregate level cannot be effectively accomplished unless properties feedback on the lower level through a complementary process of immergence into behaviours of units at the lower level. In complex social systems, where units at the lower level include intelligent agents, the process of immergence involves agents' minds, before and in order to become visible in their behavior. (p. 1)

Hence, we must look not only in one "direction" (from smaller to larger systems), but simultaneously in two "directions." The idea of immergence is important because it further erodes the notion of hierarchy.

Lastly, a complex human system simultaneously exists both as itself and, insofar as humans can be reflective, outside itself looking in. Kampis (1994) refers to this type of observation - where the observer is part (or all) of the system being observed - as an endophysics view. This endophysics view requires a certain type of reflexivity. Reflexivity in complex systems requires a different approach to study than the usual separation of observer and observed (Ricca, 2008).

\footnotetext{
${ }^{7}$ From here on, we will restrict ourselves to looking at human systems and social systems that have humans as members.

${ }^{8}$ There is something important about time scales, however, that we will return to later.
} 
All of these, put together, create a sort of Klein bottle topology of human complex systems. This is important for two reasons. First, it implies that what is important about human complex systems is not merely the geometry of the system (with its usual approach to measurement, etc.) but also the topology of a system, the interconnections between components. Second, it implies also that the commonplace (linear, modernist) logic used to examine systems might not work as one intends it.

It is not merely the topology of human complex systems, however, that is important to consider. Additionally, complex systems in relationship to one another are often enmeshed with each other. It is common that we study systems with clear boundaries between them. Countries, for example, have (usually) well defined - if disputed borders separating them. However, in nonlinear systems, there are often regions where the boundaries themselves are not easily defined.

One example of such a problematic boundary occurs in the Sierpinski triangle. Fractal figures such as the Sierpinski triangle demonstrate the enmeshed nature of different systems - in this case, the systems are the two different colors that make up the figure - and also allow us insight into the process that creates enmeshed systems. The enmeshed parts are created by an iterative process in which two systems mutually influence each other (here, through the exchange of colors). Although some regions of one color of the triangle are easily separated from regions of the other color (e.g., the central triangular region), there are many small neighborhoods in the triangle where one color is not separable from the other. In these neighborhoods, it is true that a point of one color is infinitely close to a point of the other color and that the actual determination of the color cannot be made without infinite precision in the location. Hence, the boundaries between the colors are not clearly delineated and as one takes a closer look at a region of the boundary, the picture gets no clearer. In this case, we can say that the boundaries are fractals. Even more importantly here, in these neighborhoods there is never a situation where one color is clearly on one side of a "dividing line" and another basin on the other. The various colors are enmeshed and no full separation of one region from another is possible. In such cases, the more clearly one attempts to define the boundaries by looking closely, the more enmeshed the colors become.

Because of the lack of clear boundaries, it becomes impossible for two regions to be fully disentangled from each other. The system with which another system is enmeshed is not analogous to a coat (or even a skin) that can be shed. Instead, one system is inseparable from the other system. Hence, to speak of the systems as "separate" or having a "mutual influence" on each other is to at least partially miss the essential nature of these complex systems; there are situations where it does not fully make sense to consider the components of a complex system as "separate" (and probably does not fully make sense to consider "components," although that will be harder to avoid). Failure to recognize this level of complexity is to remain unable to escape the old ideas of linearity and reductionism. ${ }^{10}$ It is important that we keep this difficulty firmly in our view as we move forward, lest we become like Sisyphus and remain bound by reductionism.

The nonlinear connectedness of complex human systems - as indicated by the Klein bottle structure and the enmeshing of component systems - forces us to consider ourselves and our social and educational systems as existing in multiple components at

\footnotetext{
${ }^{9}$ A Klein bottle can be created either by connecting the edges of two Möbius strips, or by taking the neck of a bottle and passing it through the bottle to connect back up with itself. Neither of these constructions is possible in normal three-dimensional space, however.

${ }^{10}$ In this respect, we are like Sisyphus, condemned to pushing a rock up to the top of a hill but because we never get over the top, we decay back to an earlier approach. Unlike Sisyphus, our plight is probably not due to a vengeful Hades, but rather is more likely due to the roads taken by our intellectual ancestors. Hence these ideas are part of our culture and/or paradigm in the Kuhnian sense, and will probably be quite difficult to fully overcome.
} 
the same time: In enmeshed complex systems each exists simultaneously "inside" the other. The temptation, and the commonplace practice, has been to focus on only one component at time, but that approach is not amenable to the systems we are now considering.

As an example, the psychological approach to science education (typified by the conceptual change approach) has been replaced in some places by a more sociological (and/or cultural) approach, with relatively little discourse between the two (Roth, 2010). However, it is my claim that neither approach will ultimately succeed because each fails to fully appreciate and deal with the nonlinearly connected nature of the psychological and the social. We can examine the components of this particular problem, but it is the connectedness - Bateson's "pattern that connects" - that matters.

\section{Commonplace method and complexity}

Education viewed as a complex system provides three critiques of the commonplace methods of teaching. First, the complex notion of growth critiques the usual planning and implementation of lessons. Second, the mutual influence of complex systems stands in opposition to the commonplace delivery of content. And third, the nonlinear connectedness of complex systems points to an interweaving of novice, expert and discipline that is often missing in teaching.

\section{Planning for growing systems?}

Teachers are usually taught to plan lessons and units in a manner that fails to recognize the growth nature of students. Lessons are predicted to move students from not understanding a subject to understanding that subject, despite the inability to control or predict complex (growing) systems, and despite the fact that these lessons are planned without any input from students.

Further, the structure and delivery ${ }^{11}$ of these pre-planned lessons implies that teachers can sequentially and "logically" add parts to student understanding, just as an assembly line adds assemblies to a car in sequence ${ }^{12}$. Students and their understandings, however, grow, and the "logic" of their growth may not be the "logic" of the final product: Students bring forth (Proulx, 2008) their world. In the end, the cognitive edifice of students may have great coherence and "logic", and may resemble an accepted disciplinary structure, but during the bringing forth, this may not be so.

Much more has been said about this sort of bringing forth. Varela, Thompson and Rosch (1991), considering the autopoietic nature of knowers, say much about the relationships between observers, knowers, the environment, structure and lived history of the knowers, and the world that is brought forth through their interactions. Commonplace planning fails to recognize the autopoietic nature of learners, and hence fails to capture the essence of learning and teaching. Furthermore, Piaget, who was not explicitly acknowledging that learners are autopoietic systems, also noted the difference between the logic of the learner and the logic of one who already knows (Piaget, Garcia, Davidson \& Easley, 1992). While a fuller discussion of autopoiesis and planning is beyond the scope of this piece, it suffices to note that commonplace planning for instruction fails to recognize the "bringing forth" that occurs during the growth of a complex system.

\footnotetext{
${ }^{11}$ Note well the connotations of "delivery".

${ }^{12}$ In fact, the entire progression from kindergarten through the end of secondary school seems to reflect the same thing. Put a five year-old in at one end of the education-assembly line, have each teacher-worker add the appropriate piece, and a high school graduate - different from all the other high school graduates only in color and a few other options (some of which are available at no extra charge!) - will appear at the other end.
} 


\section{Mutual influence?}

In addition to the predictive and assembling nature of commonplace teaching, there is a further problem. Commonplace teaching introduces a disconnect between the students and what the students are supposedly studying, the disciplinary canons. In a sense, this is a violation of the tenet of constructivism that the knower be actively involved with the known. However, complexity refines this notion: As both students and the disciplinary canons that commonplace teaching attempts to impart to them are complex systems, it is important that teaching allows for the mutual influence that is essential to the interactions of complex human systems. In a very real way, both the students and the subject of their study must be changed by the study. However, what often is expected of students - rote memorization of facts or the routine performance of given algorithms attempts to change the student (read: "student's behavior") without changing the subject of study. By so limiting the relationship between the student and the subject, both complex systems become fragmented, and students' experience of school becomes one of disconnect. In essence, commonplace methods destroy the "patterns that connect" (Bateson, 1988, p. 7) by reducing complex systems to only one or a few of their aspects.

This complexity reduction of commonplace instruction is an attempt to control students' ultimate understanding. It is an attempt to control the uncontrollable, to direct the growth of an autopoietic system. Autopoietic systems, by definition, direct their own growth. Because of the mismatch between the aims of this instruction and the reality of those being "instructed", a great deal of stress, energy, and financial resources go into the attempt for control, usually without much success. (We will later see additional ways in which there is a mismatch between instruction and those being "instructed" when we look at student stances towards a discipline.)

One source of this disconnect is that the time scales over which a student learns and the time scales over which a discipline changes are usually quite different. Students typically engage with and learn school topics over a span of days or weeks, even though they may refine their understandings over a period of years. The disciplines that students learn about, however, typically change over periods of years or longer, and are changed by people who engage with the discipline over those time spans. Researchers must have a "very long attention span" (Weinreich, 1991) as the mutual influence of researcher and discipline - both complex systems - occurs over a long time. The time spans over which influence is exerted must, in some sense, be roughly the same for two complexly interacting systems. Students, because they are presented only the unchanging $^{13}$ canon of a discipline, find very little with which to interact.

An additional contributor to the disconnect is that, too often, in commonplace teaching, the subject matter is "taught" by the teacher who "knows" the subject; the teacher then attempts to impart her or his knowledge to the students. In a very real sense, the student-teacher-subject relationship of commonplace teaching looks like this:

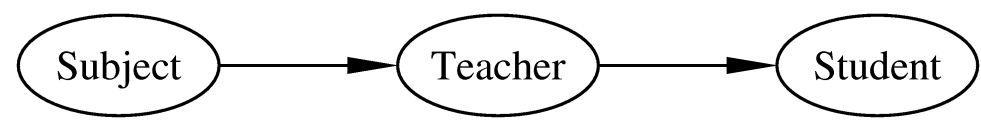

In this way, by delivering the curriculum to the student, the teacher also serves to buffer the subject from the unwanted intrusion of the student, while at the same time preventing the student from interacting directly with the subject. Jardine (2006) refers to this type of teaching as treating the subject as a scarce resource to be protected and rationed.

${ }^{13}$ In fact, very slowly changing, relative to the semester or year a student spends in a course. 
A more relational student-teacher-subject relationship could be pictured like this:

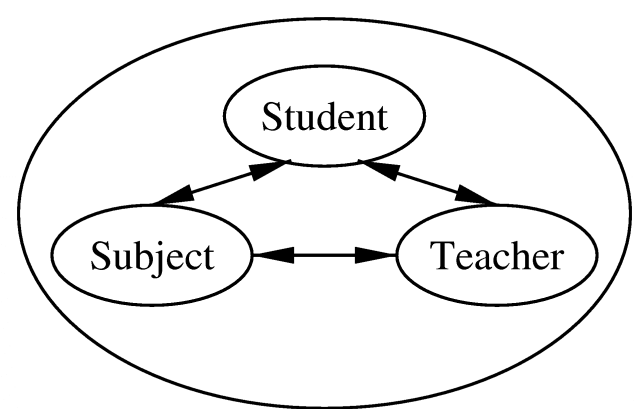

In this picture, the teacher still stands in relationship to the student and to the subject matter ${ }^{14}$, but each of the three can be changed by the other, and, in analogy to Mary Catherine Bateson's psychotherapy work presented earlier, the learning occurs in the system and not merely in the student. ${ }^{15}$

Failure to allow mutual influence not only cuts the student off from the discipline, it also impoverishes the discipline: Students fail to learn what is truly important about a discipline, and, once out of school (whether for the day or permanently) they do not think to turn to a discipline for insight and do not see the wonder that those who practice the discipline see. For these reasons, the disciplines themselves become cut off from the daily living of most people.

There is another way that a failure to allow mutual influence manifests itself in classrooms. Teachers commonly get many questions similar to "When will I ever need this?" These questions, which are questions of influence, take many forms. While teachers usually answer this question as if extrinsic motivation will work - e.g., "Someday, it will be important" - this ignores a larger issue. A better view of this question is to interpret this as "How can I complexly (i.e., with mutual influence) participate in this endeavor?" The question is one prompted by feelings of powerlessness, of feeling disrespected and of feeling cut off from the material rather than any real need to reap a future reward.

According to Wolfram (2002), complex systems can be thought of as existing in one of four categories; these categories describe the behavior of the system under various constraints and conditions. Such taxonomies, rather than trying to reduce the complexity of the system, are intended instead to help external observers begin to make sense of the system's behavior. Questions of connection can help us see that students belong to one of four categories in parallel with Wolfram's taxonomy:

1. Some students have "checked out" completely. These students will not engage with the subject, no matter what. These students never ask questions of connection, for they desire no connection. The subject has no influence on the student, and the student sees no influence on the subject. ${ }^{16}$

2. Some students are engaged with the subject in a non-complex manner. These students recognize that their (intended) future career requires them to

\footnotetext{
${ }^{14}$ And each of these three - student, teacher and subject - are themselves complex human systems.

${ }^{15}$ Even still, this picture is lacking, for it fails to consider the other systems of which the studentteacher-subject are a part, and fails to consider student-student interactions, and so forth. However, none of those connections are needed for the argument that follows, so a simpler (reduced) picture is, in this case, not overly incorrect.

${ }^{16}$ There are many possible paths that result in students "checking out", but those are not relevant to the analysis here.
} 
demonstrate so-called "mastery" of the material, or that they will please authority figures (or at least avoid their displeasure) by conforming to the teacher's desire. These students never ask questions of connection, for they desire no connection beyond the one they have. In these cases, the subject has only a transitory and limited influence on the student - just enough to pass the required assessment - and the student does not change the subject in any way.

3. Some students are engaged with the subject complexly. These students see the beauty in a subject, or are otherwise engaged purely for the desire to be engaged. In cases such as this, study for study's sake is sufficient, as is appropriate in autopoietic systems. These students also never ask questions of connection, for they are already connected with the subject. They are often deeply influenced by the subject, and, at least in their own experience, feel that they contribute to the subject. For example, many mathematicians can tell stories of formulae or theorems that they invented on their own, only to find out later that someone had discovered the same thing years earlier. ${ }^{17}$

4. Some students are searching for a connection to the subject. These are the students who do ask questions of connection, which, if answered appropriately, may help those students find ways to engage complexly with the subject. Inappropriate answers - which include ignoring the question and many of the commonplace answers - may lead to students to join the first or second of the categories here.

One additional point about these categories of students is salient: Thelen and Smith (1995) note that teleology is not a good driver of development. However, it can be seen that students who engage non-complexly are motivated by teleology, but, in accordance with Thelen and Smith's claim, do not develop in relation to the subject. Students who have checked out or who are complexly engaged are not motivated by teleology ${ }^{18}$.

\section{Connections?}

The connectedness of complex systems - both considered in their individuality and as enmeshed with other complex systems - provides a third critique of commonplace teaching. To study mathematics ${ }^{19}$, for example, students must participate in the community of mathematics ${ }^{20}$ (Lave \& Wenger, 1991). As both students and the community of mathematics are complex systems, to interact each must exist within the other and be enmeshed with the other; and the two cannot be separated. Hence, the mathematics community must be created by the students even as the students are created as mathematicians by mathematics. This process of enculturation - which is essentially (re-)creating a culture while being (re-)created by that culture - is ignored by commonplace methods. Failure to consider enculturation, like the failure to consider the mutual influence between complex systems, results in fragmentation and experiences of disconnect.

Given these critiques of commonplace methods in teaching, it is important to examine some alternatives.

\footnotetext{
${ }^{17}$ In my experience, none of these mathematicians has been disappointed or deterred by not being the first. The experience of creativity is sufficient.

${ }^{18}$ Or at least, there is more to their motivation than simply teleology.

${ }^{19}$ The author is a faculty member in a mathematics department, so my examples naturally come from that discipline.

${ }^{20}$ Although I greatly admire of the work of Lave and Wenger, I believe that the appropriate term is the community is of mathematics and not only of mathematicians. The latter would imply that only the people are complex and that mathematics can be reduced to its component mathematicians. I believe that to be an inappropriate form of reductionism.
} 


\section{Teaching: A complexity approach}

There are many approaches to school and study that a complexity approach does support. Some of these approaches are similar to ones promoted elsewhere, but gain new insights from complexity (e.g., Davis \& Simmt, 2006), while others are closer to being unique to a complexity view. Four will be examined here, and although they are presented in sequential fashion - again, a limitation of textual approaches - all four are enmeshed within each other. The four aspects of complex teaching are a need for mutual influence, enculturation (considered in light of mutual influence), the necessity of reflection (on the part of both students and teachers), and the important role of improvisation.

In all of what follows, Block's (2004) point about study is important: "Study... is a way of being" (p. 2). What is being presented is not merely a goal or an outcome. Instead, these components must be seen as an ongoing process that teachers engage in constantly. Further, teachers must engage their students in engaging in this same process of studying.

\section{Mutual influence}

All study must involve mutual influence. It has been said that teachers must know their students, but usually what is meant is not that the teacher is to be transformed, but rather that the teacher can, by knowing her or his students, more efficiently move the students to a desired understanding. However, a complexity approach suggests not only that attempts such as efficiency are misplaced, but also requires that teachers must be transformed by their students as a result of the mutual influence of teachers and students. The necessary transformation of students and teachers is seen in authors such as Noddings (1992) and hooks (2003).

Further, the discipline that is studied must be influenced by the students. It is not sufficient, for example, that students attempt to absorb insights from the canon of the professional mathematician; this canon is rarely influenced by students, and so a mutual influence is lacking. Instead, students must co-create classroom mathematics rather than attempt to absorb the finished ${ }^{21}$ product of professional mathematicians. Attempts to impart the canon of mathematics to the students treat both the student (who is then considered to be non-autopoietic) and the canon (which is stripped of its processes) as non-complex and fragmented.

It may be argued that this process may result in students not "getting it right". However, from a complexity perspective - and this corresponds to the experience of teachers - there is no way to guarantee that all students "get it right". Additionally, complexity argues that one role of the teacher is to promote ongoing mutual interactions (such as play and exploration) between the students and the raw materials studied by professional mathematicians, trusting that the students and mathematics will come into coherence with each other over time. ${ }^{22}$ While it may be true in the end that the classroom concepts of mathematics are very similar to the mathematicians' concepts, this end result is not the goal of study. The goal of study - (again) for autopoietic systems - is study itself. That the outcomes of this study may be aligned with what is desired by an external curriculum or school system is a happy by-product that comes about because of the ongoing interactions.

\footnotetext{
${ }^{21}$ Again, "finished" merely means something that changes much more slowly than over the days or weeks of a unit of study in schools. It does not mean that mathematics is perfect and unchanging.

${ }^{22}$ I am quite confident in making this statement regarding maths and science learning. I am fairly confident that this is true of language learning. Beyond that, I suspect that I am correct, but I have little experience actually teaching other disciplines.
} 
An aside on this point is perhaps useful. When students approach a discipline, such as mathematics, in this way, there are at least five interacting complex systems: the students, the mathematical community of the classroom, the mathematics of the classroom, the community of professional mathematicians, and the accepted canon of mathematics. Although each of these systems can develop according to their own internal norms, by continuing to have interactions with each other, the structural coupling (Maturana \& Varela, 1992) will bring all five into some reasonable alignment. Hence, even without focusing on students learning the accepted canon of mathematics, a commitment to the interaction between the various interacting systems will still bring about the result desired by standards: Students will have ideas that are aligned with the accepted canon. In fact, students who pursue a discipline deeply enough find themselves becoming enmeshed with that discipline's community and canon; after some time, those three systems cannot be separated.

\section{Enculturation}

To truly study a discipline, students and teachers must be enculturated into that discipline. Merely playing with and exploring a discipline are not sufficient for study. Returning to mathematics, we can define mathematics to include the mathematicians who undertake work in mathematics, the process of mathematizing and the canon of mathematical results. Because mathematics includes the people who work in the field, mathematics is continually (re-)created by those who are (re-)created by the field. Students - and teachers - must create the disciplinary culture they study. Students who study math must do so as mathematicians and must create a community of practice (Wenger, 1999), even if they do so not do so as professionals.

Enculturation via a community of practice is precisely the type of approach that is necessary for the growth of complex systems. By focusing on enculturation in the school experience, the students can grow (as opposed to "be constructed") and the classroom also grows. The creation of a community of practice - and the resulting (re)creation of a culture as the students are (re-)created by the culture - also allows for the mutual influence and patterns of connection that are required by complex systems. This process is much the same as Donald's (2001) argument that human consciousness is just such an interplay between individual and culture.

This culture creation is unlike African termites, for instance, that build great patterned structures from their simple interactions. In the case of termites, the resulting structure is obviously constructed, and can exist after the termites have left. Human interactions, however contribute to cultures in addition to mere patterns. These cultures, for instance, do not exist without the humans who contributed to them. Further, unlike the structures of termites, human cultures have a different type of influence on the humans who participate in them: Termite structures have no lasting influence on termites, but cultures are things that humans "carry" with them wherever they go. In fact, human cultures are largely enmeshed with those who participate in them.

\section{Reflection}

Because students and teachers exist in multiple relationships to a discipline - as outsiders to a disciplinary culture, members of that culture, and creators of that same culture - reflection (Ricca, 2008) is a necessary component to study. It is only through a process of reflection, whereby one studies one's self studying, that we can integrate the various components of the self. Without such reflection, fragmentation of the person and disconnect from the discipline result.

This reflection is especially important for teachers, who must simultaneously participate in the disparate cultures of content experts (the disciplinary professionals who know and understand), content novices (the students who neither know nor 
understand), and school representatives (who have entirely other constraints imposed by the expectations of parents, administrators, etc.). The ability to bring forth a teacher from these disparate cultures, rather than merely navigate through the cultures sequentially, requires reflection. Teacher preparation programs must promote the discipline of reflection in their candidates.

\section{Improvisation}

Because complex systems bring their histories with them and are enmeshed with other complex systems, teachers must be "sensitive to the ongoing life and experiences of themselves and students in the situation" (Aoki, 2005, p. 370). This sensitivity, which Aoki refers to as improvisation, requires a deep content knowledge, an ability to embody that knowledge, and a willingness to let that knowledge go in favor of the knowledge of others. Teachers must be able to simultaneously exist with the permanence (the immutable $^{23}$ canon of the discipline) and the flux (the classroom exploration), recognizing that both are necessary components of growth process (Whitehead, 1979).

Put another way, it is important for teachers to listen to their students with a stance of always asking "What more?" (Tobin, 2010). The purpose here is not necessarily to remove formal assessment and judgment from the process - in the end, teachers in today's schools will likely have to assign grades $^{24}$ - but rather to suspend judgment in favor of further exploration of the students' meanings, histories, and cultures. It is this ability to follow a student wherever she leads and do something helpful in response that requires improvisation on the part of the teacher.

The ability to improvise is developed through playing, which is a special type of practice. Commonplace use of the term "practice" connotes an attempt to accurately mimic or reproduce something. There is, however, another approach to practice: Musicians practice not only to mimic something, but also to interpret, to add something, to adjust things so that all the parts fit together, and in many cases, so that they can clear space in which the music can be created (Fleener \& Matney, 2006). Bullock (2010) noted the importance of pre-service teachers getting to explore teaching - to practice in the musical sense - rather than just practicing (in the mimicry sense) what has been held up to them as a model. This improvisation asks teachers to do more than just "teach as they've been taught" (in the sense of Shulman, 1986); teachers must create classrooms, often in ways and situations that their teachers could not have anticipated.

All four of these components - mutual influence, enculturation, reflection, and improvisation - can and should be implemented within teacher education and professional development activities.

\section{Possibilities: Preparing teachers beyond methods}

Both the published literature and our own personal experiences are full of examples of classrooms that have moved beyond mere methods. To bring more concreteness to the current exploration, two examples here will guide an exploration of new ways of preparing teachers. Although these two examples are math and science classrooms, I believe that the processes demonstrated by these classrooms likely apply to all content areas, at least insofar as all classrooms are complex systems.

\footnotetext{
23 "Immutable" here means that changes occur on a time scale much, much longer than a single class or unit. All disciplinary canons presented to students as immutable actually do exist as complex systems, and hence do grow over time. I do not believe that Whitehead would object to this characterization.

${ }^{24}$ Although it is not the purpose of this paper to argue against assigning grades, I will note that grades merely compare a complex learner to a non-complex template, and really say little meaningful about the learner.
} 


\section{Examples}

The work of Constance Kamii (2000) demonstrates a number of the important components of a classroom without methods. In her approach to the learning of mathematics by young children, the students spend time playing games (in kindergarten and first grade) and then spend time solving problems (in second and third grade) all without any direct instruction by the teacher. In these classrooms, the validity of any procedure or answer is determined by a careful discourse between the students, and not through the approval of the teacher. The teacher creates an environment where all students must develop their own approaches and then expose those approaches to the rest of the students in the classroom. In this way, students are enculturated to a process of mathematizing. Like professional mathematicians, the students create methods to approach problems and test those methods against their colleagues. In this process, the students and the mathematics of the classroom are constantly changing and changing one another through their mutual influence. Students in these classrooms reflect on their own work, for they demonstrate an ability not merely to disagree with their classmates, but on occasion, a student becomes aware that $\mathrm{s} / \mathrm{he}$ disagrees with her-/him-self. Through this process, the students create their own approaches to mathematics rather than attempting to absorb the "correct approach" from the teacher or a textbook. Often a resulting method will look similar to the standard algorithm, but that is again, a happy by-product.

The individual students, the teacher, the classroom community, and the mathematics in these classrooms act as complex systems. Each grows in an organic manner rather than through a planned sequence of added knowledge. The students clearly have a mutual influence, arguing with each other and sometimes changing in response to those arguments. The mathematics of the classroom has an influence on the students, and the students create that mathematics. As time goes on, the students more deeply adopt the process of argumentation and begin to have their methods align with the common mathematics; through the exchanges of the classroom, the students and the mathematics become enmeshed.

The teachers in these classrooms must also embody a complexity approach. The teacher becomes the door through which the accepted mathematical canon comes into the classroom, but must do so without becoming the authorized transmitter of mathematics. The teacher can introduce mathematical situations (through the choice of games, puzzles, or problems) and promote the culture of mathematics (a process of argumentation) while simultaneously not attempting to control the students. The mathematics that is brought to the students is a result of the teacher's reflection on the situation; while many things are prepared ahead of time, it is only in the teaching that the teacher knows what mathematics to bring to which students. In other words, the teacher is influenced by many systems, and exerts an influence on them. Likewise, the teacher must make decisions based on a process of reflection on what $\mathrm{s} /$ he is learning from the students. To know, however, what is appropriate requires the teacher to be intimately familiar with mathematics and the process of mathematizing. In other words, the teacher must be, to some extent, enculturated in mathematics (see Ball, 2011, for a further exploration of this point). Lastly, because s/he does not know the students' products ahead of time, and does not have in mind any single archetype for the students to mimic, the teacher must be very good at improvisation.

While Kamii (2000) examined very young students, Smithenry \& Gallagher-Bolos (2009) and Patchen \& Smithenry (2011) examined classrooms of adolescent students. These inquiry classrooms value organization and ordering, communication, and disciplinary warrants (Patchen \& Smithenry, 2011). Although the terminology is different than what is used here, the outcomes are much the same: students are enculturated into an approach to science that values mutual influence and reflection on the part of students, 
and this requires the teacher to improvise in response to student actions. While the details of a high school inquiry science class are different from those of an elementary school mathematics class, similar dynamics, and similar demands on the teacher, exist. Further, students in carefully implemented inquiry classrooms perform better than in traditional classrooms on commonplace "high stakes" assessments, indicating the effectiveness of inquiry approaches (Geier et al, 2008); this is another happy by-product of teaching beyond method.

\section{Implications for preparing teachers}

Classrooms such as those studied by Kamii (2000), Smithenry \& Gallagher-Bolos (2009) and Patchen \& Smithenry (2011) require teachers to have habits of teaching other than commonplace methods. There are, fortunately, approaches to teacher education that can promote the development of the appropriate practices. These require teacher preparation to adopt different stances towards planning, assessment, curriculum, and field experiences. Some points of importance are presented below.

One important piece is that planning and assessment in teaching must be reconceptualized. While approaches such as "backward design" (Wiggins \& McTighe, 2005) represent some of the "best" of the commonplace methods, these approaches still plan the curriculum largely in the absence of the students: Lesson plans and unit plans are all completed before the teacher even meets the students who will be subjected to those plans. In this way, there is little room or value for mutual influence (of students and teachers) or teacher improvisation. Instead, students are treated as the product of an assembly line, where the students are "designed" well ahead of time. Assessment then compares the resulting students to a pre-determined template, and is a measure of quality control: In this procedure, both students and teachers are determined to be either acceptable or not.

To break away from this type of teaching, planning must take on a different purpose. Planning, the usual production of lesson plans and units, must be replaced with a different type of preparation. This preparation begins with teachers becoming enculturated into a discipline and, ultimately, enculturated into a way of teaching that is different from the commonplace. The former enculturation allows teachers to more fully know the disciplinary terrain that students will later explore. Coupled with an understanding of what emotional terrain students may be exploring, this process can open teachers to the mutual influence of students, allowing teachers to serve as a sort of guarantor of the study process, as opposed to the deliverer of content knowledge.

This type of planning is considerably more difficult and time-consuming than the commonplace planning, as the teacher must prepare for many possible paths that the class may take. This requires the teacher to explore a great deal of territory that will probably (because of time limitations or the interests of students) not be part of the class, and requires the teacher to make many hypotheses about what students may do and what might be appropriate responses. Not only are good hypotheses difficult to make, in the education realm teachers must hold their hypotheses intentionally unresolved while actively listening for students to present "data" that pertain to the hypothesis. This sort of planning, listening, and responding not only is reminiscent of Aoki's (2005) call to improvisation, but it recognizes that students and teachers have a nonlinear connectedness, which requires the adoption of a strategic approach rather than a programmatic one (Alhadeff-Jones, 2009).

In this type of planning, syllabi, except perhaps in their broadest strokes, must come from the interplay of students and teacher and hence should be completed only after the course begins $^{25}$. Despite the difficulties involved, this approach is one that allows for

\footnotetext{
${ }^{25}$ Even then, the syllabi will probably need to be revised frequently; perhaps syllabi are best conceived as a history of the course that is completed only after the course is finished.
} 
mutual influence even as it requires both reflection and improvisation by the teacher. This preparation respects the complex nature of the teacher, the students, and the discipline.

Assessment must also be changed. As growing systems, rather than assembled ones, the standardization of students is not the goal. The fitness of a learner, in the sense of how fit an organism is to its environment, cannot be determined by the comparison of a student's responses to a pre-determined template. This notion, expressed in other words, has been around at least since Vygotsky and the concept of the zone of proximal development (ZPD) (1978): Current codified abilities really do not predict anything about future learning. Hence, other means of assessment are necessary, and teachers must be prepared to participate in these other means.

One type of assessment that is more commensurate with students as complex systems is dynamic assessment (Lidz, 1987; Sternberg \& Grigorenko, 2002). In dynamic assessment, instruction occurs at the same time as the assessment, and there is a very tight feedback loop involving the learner, the content, and the teacher/assessor. This tight feedback loop allows for the teacher/assessor to better use the information from assessments to guide learning. This approach is similar to other ways of dealing with chaotic systems, and dynamic assessment has shown success in several contexts, mostly, however, dealing with education of exceptional learners.

However, there is another approach to assessment that more readily recognizes the complexities of learners. Teachers must be enculturated into a discipline well enough to recognize the mutual interaction of the discipline and the students, and to bring student attention to that mutual interaction (Ball, 2011). The ability to do this requires a certain amount of reflection on the part of the teacher in addition to just the disciplinary ability. A former colleague used to put the following at the end of his e-mails: "Those who can, do. Those who really understand, can teach" (Tom Senior, private communication). It is, therefore, important for teachers to use their professional judgment to evaluate students, and to be supported for using that judgment. It is only this professional judgment, built through growth in a discipline and mutual influence with students, that allows a teacher to guide students' growth.

Commonplace, methodical curricula have been critiqued in many places (e.g., Doll, 2012). Curricula beyond method, here considered as the curriculum of teacher preparation, requires several components to be present. First, the teacher must be, at least to some extent, enculturated in the discipline to be taught. This means that, as pointed out earlier, teachers must be engaged in the on-going study of the discipline, and to be growing that way. However, teachers must also develop an ability to reflect on the process of growth, so that they can guide students appropriately: The goal is not merely for students to be able to solve certain prototypical problems, but rather for students to learn to do those as part of their own enculturation into the discipline. Guiding enculturation requires teachers to know the terrain of the discipline, the various paths that might be taken through that terrain, and also to be able to walk those other paths with their students. The last of these - for the teacher to walk paths that are not naturally her or his own - requires the mutual influence of students and teacher. With experience, a teacher will likely begin to take more of these paths as her or his own ${ }^{26}$ but the teacher will constantly need to be open to new paths and to traveling familiar paths anew.

While this approach requires that teacher preparation includes a different course of study than commonly exists, it particularly requires that teachers gain much more experience actually travelling curricular paths with students. Although most teacher preparation programs include some clinical experiences, most of these are focused on

\footnotetext{
${ }^{26}$ This process is likely what is being reflected in the statement "If you want to really learn something, you should teach it".
} 
replication of so-called "best practices" and application of what is learned in class rather than a playful experimentation with designing different learning environments and the opportunity to work with students to explore many different paths, and so on. Furthermore, clinical experiences should exert a mutual influence with the course work: courses are not merely to be applied to the clinical experiences, but the clinical experiences should also direct the courses. Such an approach enculturates students into a view of teaching that involves reflection, mutual influence, and improvisation.

Hence, in parallel with Aoki's (2005) approach to practice and improvisation, preservice (and in-service) teachers must have consistent opportunities to be playful with curriculum. Planning (complexly) is important, but skills and abilities are developed through pushing boundaries, and it therefore is important for teachers to practice (in the musical sense) curriculum. While it might be ideal for this practice to be part of all experiences of teaching, in the current climate, it may be necessary to take advantage of informal education settings (e.g., science museums, after school "enrichment" offerings, summer camps). These opportunities can be added to teacher education, even in the current climate, and would be beneficial to the teachers.

\section{Conclusions}

A complexity approach to education critiques the commonplace methods of teaching, and offers alternatives to teaching and teacher preparation. By considering students and the subjects they study as complex entities, insight into the limitations of commonplace methods - the difficulty of planning without reference to the students in the class and the potential for fragmentation and disconnectedness - can be gained. Approaches to teacher preparation that address these limitations - by recognizing the importance of improvisation, reflection, mutual influence, and enculturation - could be used in education.

\section{References}

Alhadeff-Jones, M. (2008). Three generations of complexity theories: Nuances and ambiguities. Educational Philosophy and Theory, 40(1), 66-82.

Alhadeff-Jones, M. (2009). Revisiting educational research through Morin's paradigm of complexity. Complicity: An International Journal of Complexity and Education, 6(1), 61-70.

Andrighetto, G., Campennì, M., Conte, R., \& Paolucci, M. (2007). On the immergence of norms: A normative agent architecture. In Proceedings of AAAI Symposium: Social and Organizational Aspects of Intelligence, Washington DC.

Aoki, T. (2005). Sonare and Videre: A story, three echoes and a lingering note. In W. Pinar, \& R. Irwin (Eds.), Curriculum in a New Key: The Collected Works of Ted Aoki (pp. 367-376). Mahwah, NJ: Lawrence Erlbaum.

Ball, D. (2011). Foreword. In M. Sherin, V. Jacobs, \& R. Philipp (Eds.), Mathematics teacher noticing (pp. xx-xxiv). New York: Routledge.

Bateson, G. (1988). Mind and nature: A necessary unity. Cresskill, NJ: Hampton Press.

Bertuglia, C., \& Vaio, F. (2005). Nonlinearity, chaos \& complexity. New York: Oxford University Press.

Block, A. (2004). Talmud, curriculum, and the practical: Joseph Schwab and the Rabbis. New York: Peter Lang.

Bullock, S. (2010). Beyond "Repeating the Textbook" and "Problem Solving": Teacher candidates talk about learning to teach physics. Paper presented at the 2010 Annual Conference of the National Association of Research in Science Teaching in Philadelphia, PA.

Cilliers, P. (1998). Complexity and postmodernism. New York: Routledge.

Cohen, J. \& Stewart, I. (1995). The collapse of chaos: Discovering simplicity in a complex world. New York: Penguin Press.

Crutchfield, J. (1994). The calculi of emergence: computation, dynamics and induction. Physica D, 75, 11-54.

Davis, B., \& Simmt, E. (2006). Mathematics-for-teaching: An ongoing investigation of the mathematics that teachers (need to) know. Educational Studies in Mathematics, 61, 293-319. 
Davis, B., \& Sumara, D. (2006). Complexity and education: Inquiries into learning, teaching and research. Mahwah, NJ: Lawrence Erlbaum.

Doll, W. (2002). Beyond methods? Teaching as an aesthetic and spirit-full quest. In E. Mirochnik \& D. Sherman (Eds.), Passion and pedagogy: Relation, creation, and transformation in teaching (pp. 127-151). New York: Peter Lang.

Doll, W. (2012). Complexity and the culture of curriculum. Complicity: An International Journal of Complexity and Education, 9(1), 10-29.

Donald, M. (2002). A mind so rare. New York: W. W. Norton.

Fleener, M., \& Matney, G. (2006). Curriculum clearings as being-with-mathematics experiences: Authentic learning through a Heideggerian lens. Journal of Curriculum \& Pedagogy, 3(2), 92-106.

Geier, R., Blumenfeld, P., Marx, R., Krajcik, J., Fishman, B., Soloway, E., \& Clay-Chambers, J. (2008). Standardized test outcomes for students engaged in inquiry-based science curricula in the context of urban reform. Journal of Research in Science Teaching, 45(8), 922-939.

Gould, S., \& Eldredge, N. (1977). Punctuated equilibria: the tempo and mode of evolution reconsidered. Paleobiology, 3(2), 115-151.

Holland, J. (1998). Emergence. Cambridge, MA: Perseus Books.

hooks, b. (2003). Teaching community: A pedagogy of hope. New York: Routledge.

Jardine, D. (2006). Preamble I: From scarcity to improverishment. In D. Jardine, S. Friesen, \& P. Clifford, Curriculum in abundance (pp. 13-17). Mahwah, NJ: Lawrence Earlbaum.

Jones, R. (1981). Some consequences of physics. Nature, 293, 23-25.

Kamii, C. (2000). Young children reinvent arithmetic: Implications of Piaget's theory. New York: Teachers College Press

Kampis, G. (1991). Self-modifying systems in biology and cognitive science. New York: Pergamon Press.

Kampis, G. (1994). Biological evolution as a process viewed internally. In H. Atmanspacher, \& G. Dalenoort (Eds.), Inside versus outside: Endo- and exo-concepts of observation and knowledge in physics, philosophy and cognitive science (pp. 85-110). New York: Springer-Verlag.

Kaneko, K. (2006). Life: An introduction to complex systems biology. New York: Springer-Verlag.

Langton, C. (1986). Studying artificial life with cellular automata, Physica D, 22, 120-149.

Lave, J., \& Wenger, E. (1991). Situated learning: Legitimate peripheral participation. New York: Cambridge University Press.

Lidz, C. (1987). Dynamic assessment: An interactional approach to evaluating learning potential. New York: The Guilford Press.

Maturana, H., \& Varela, F. (1992). The tree of knowledge: The biological roots of human understanding. Boston, MA: Shambala.

Noddings, N. (1992). The challenge to care in schools: An alternative approach to education. New York: Teachers College Press.

Patchen, T., \& Smithenry, D. (2011). Framing science in a new context: What students take away from a community of practice. Paper presented at the 2011 Annual Meeting of the American Educational Research Association in New Orleans, LA.

Piaget, J., Garcia, R., Davidson, P., \& Easley, J. (1992). Toward a logic of meanings. Florence, KY: Psychology Press.

Proulx, J. (2008). Some Differences between Maturana and Varela's Theory of Cognition and Constructivism. Complicity: An International Journal of Complexity and Education, 5(1), 11-26.

Prigogine, I. (1984). Order out of chaos. New York: Bantam.

Ricca, B. (2008). Enframing: The view from inside. Complicity: An International Journal of Complexity and Education, 5(1), 115-121.

Rosenberg, B. (1990). Gould promotes the entity theory of evolution. The Tech, 110(56). Friday, December 7, 1990. Retrieved from http: / / tech.mit.edu/V110/ PDF / N56.pdf.

Roth, W.-M. (2010). ReUniting sociological and psychological perspectives in/for science education: An introduction. In W.-M. Roth (Ed.), Re/structuring science education: ReUniting sociological and psychological perspectives (pp. 1-12). New York, NY: Springer.

Seltzer-Kelly, D., Cinnamon, S., Cunningham, C., Gurland, S., Jones, K., \& Toth, S. (2011). (Re)imagining teacher preparation for conjoint democratic inquiry in complex classroom ecologies. Complicity: An International Journal of Complexity and Education, 8(1), 5-27.

Shulman, L. (1986). Those who understand: Knowledge growth in teaching. Educational Researcher, 15(2), 4-14.

Smithenry, D., \& Galagher-Bolos, J. (2009). Whole class inquiry: Creating student-centered science communities. Arlington, VA: National Science Teachers Association.

Sternberg, R., \& Grigorenko, E. (2002). Dynamic testing: The nature and measurement of learning potential. New York: Cambridge University Press. 
Thelen, E., \& Smith, L. (1995). A dynamics systems approach to learning and cognition. Cambridge, MA: MIT Press.

Tobin, K. (2010). Turning to others' voices: Beyond the hegemony of mono-logical narratives. In W.-M. Roth (Ed.), Re/structuring science education: ReUniting sociological and psychological perspectives (pp. 13-39). New York: Springer.

Tyler, R. (1950). Basic principles of curriculum and instruction. Chicago, IL: University of Chicago Press.

Varela, F., Thompson, E., \& Rosch, E. (1992). The embodied mind: Cognitive science and human experience. Cambridge, MA: MIT Press.

Vygotsky, L. (1978). Mind in society: The development of higher psychological processes. Cambridge, MA: Harvard University Press.

Waldrop, M. (1992). Complexity: The emerging science at the edge of order and chaos. New York: Simon \& Schuster.

Weinreich, G. (May, 1991). Introduction to the session "Bowed strings: Honoring Carleen Hutchins." Remarks presented at the $121^{\text {st }}$ Meeting of the Acoustical Society of America. Baltimore, MD.

Wenger, E. (1999). Communities of practice: Learning, meaning, and identity. New York: Cambridge University Press.

Whitehead, A. (1979). Process and reality (corrected edition). New York: Free Press.

Wiggins, G., \& McTighe, J. (2005). Understanding by design (expanded $2^{\text {nd }}$ ed.). New York: Prentice-Hall.

Wiles, K. (1952). Teaching for better schools. New York: Prentice-Hall.

Winfree, A. (2010). The geometry of biological time. New York: Springer.

Wolfram, S. (2002). A new kind of science. Champaign, IL: Wolfram Media.

\section{About the Author}

Bernard (Barney) Ricca is the Director of the Graduate Program in Mathematics, Science and Technology Education at St. John Fisher College in Rochester, NY. He is a physicist by training and a former Chair of the American Educational Research Association Chaos \& Complexity Theories SIG. His main research interests are in complexity and in teacher preparation, and he is an avid reader and cyclist. Email: bricca@sjfc.edu

(c) Copyright 2012. The author, BERNARD RICCA, assigns to the University of Alberta and other educational and non-profit institutions a non-exclusive license to use this document for personal use and in courses of instruction provided that the article is used in full and this copyright statement is reproduced. The author also grants a non-exclusive license to the University of Alberta to publish this document in full on the World Wide Web, and for the document to be published on mirrors on the World Wide Web. Any other usage is prohibited without the express permission of the author. 